Artículo de Investigación

A puntes del CEN ES

ISSN 0120-3053

Volumen 32 - №. 56

Julio - Diciembre de 2013

Págs. 139-174

\title{
Valoración hedónica de la vivienda. Una aplicación con variables ambientales
}

\author{
Hedonic housing valuation. \\ An application with environmental \\ variables
}

Duván Emilio Ramírez Ospina* Lázaro Valencia Giraldo**

Fecha de recepción: 25 de abril de 2013

Nueva versión: 21 de mayo de 2013

Fecha de aprobación: 29 de mayo de 2013

* Ph.D en Administración, magíster en Gerencia del Talento Humano, especialista en Mercadeo, economista, decano Facultad de Ciencias Contables, Económicas y Administrativas de la Universidad de Manizales. Colombia. Correo electrónico: merca2@umanizales.edu.co, duvramirez@hotmail.com

** Magíster en Economía, especialista en Economía Avanzada, especialista en Informática y Computación, especialista en Desarrollo y Finanzas, economista, docente investigador Universidad de Manizales. Colombia Correo electrónico: valen@umanizales.edu.co 


\section{Resumen}

M ediante la utilización de técnicas de econometría espacial se estimó el efecto que tienen algunas variables ambientales en el precio de la vivienda urbana de la ciudad de Manizales, teniendo como fuente la base de datos predial con uso vivienda, resultante de la actualización realizada por el IGAC en el año 2010. Se encontró en promedio que las viviendas cercanas a las áreas de riesgo reducen su precio hasta un $11 \%$, las ubicadas próximas a una ladera en un $37 \%$ y el encontrarse en zona de tratamiento geotécnico hasta un $53 \%$.

Palabras clave: precios hedónicos, econometría espacial, heterogeneidad, autocorrelación espacial, la I de Moran.

Clasificación JEL: C21, Q 51, Q52, Q53

\section{Abstract}

Through the utilization of spatial econometrics techniques, it was estimated the effect of some environmental variables on the price of urban housing in the city of Manizales, having as a source the council tax database with resulting use of the update done by IGAC in 2010. Finding that in average houses near to risky areas reduce their price up to $11 \%$, the ones near a slope by $37 \%$ and those located in geotechnical treatment area up to $53 \%$.

Keywords: hedonic prices, spatial econometrics, heterogeneity, spatial autocorrelation, Moran's I.

JEL Classification: C21, Q51, Q52, Q 53 


\section{INTRODUCCIÓN}

Este escrito es resultado de la investigación "Valoración hedónica de la vivienda en Manizales. Una aplicación con variables ambientales", desarrollada como requisito parcial para optar al título de magíster en Economía en la Universidad de Manizales por parte de uno de los autores. En la investigación se plantea la construcción de un modelo econométrico que recoja los efectos marginales y espaciales de cinco variables atributos de la vivienda, para mirar el impacto sobre su avalúo y, muy especialmente, se observan las relaciones que tiene el avalúo de los predios con algunas variables medioambientales y se aprovecha la información que existe de variables estructurales para calcular el efecto sobre los avalúos. En primera instancia se hace una aplicación al municipio de Manizales, sin embargo, su aplicación puede hacerse en cualquier contexto, teniendo cuidado con la interpretación de los resultados y la elección de las variables ambientales de acuerdo con las condiciones del territorio donde se pretenda aplicar.

Los avalúos de las viviendas tienen una característica particular que las hace interesantes, debido a que son bienes compuestos y diferenciados en mercados muy integrados, cuya utilidad para el consumidor depende de la satisfacción que brinda cada una de las características o atributos que las componen. La idea central es que dichos atributos no se consideran por separado para fijar el avalúo, sino que se consideran en su integralidad, de una manera sistémica.

Una de las técnicas usadas para estudiar las contribuciones de cada una de esas características en el avalúo del bien 
compuesto, es la de estimar econométricamente funciones hedónicas desarrolladas por Rosen (1974) que tienen como regresores los atributos o características del bien compuesto.

En los avalúos catastrales existen interrelaciones espaciales que no son tenidas en cuenta en los modelos econométricos comúnmente utilizados. SegúnAnselin (1988a) existen dos tipos de interacciones espaciales:

La primera interacción es la dependencia espacial que se presenta cuando una de las variables explicativas tiende a asumir valores similares en unidades geográficamente cercanas. Dicha dependencia espacial es ampliamente observada en los avalúos fijados en diferentes municipios de Colombia, sin embargo en este trabajo sólo se hace referencia a lo observado en el municipio de Manizales.

Las casas de altos precios tienden a estar agrupadas al igual que las casas de bajos precios. Esta correlación espacial de los avalúos puede ser producto de un comportamiento en manada alrededor, donde las expectativas de avalúos futuros se forman con base en los valores de las unidades vecinas. Las amenidades también contribuyen a la correlación espacial, ya que los consumidores reciben utilidad positiva de vivir cerca de casas lindas y de mayor valor, lo que resulta en que casas vecinas de altos valores empujan el avalúo de todas las casas de su alrededor.
La segunda es la heterogeneidad espacial, la cual está relacionada con la falta de estabilidad en el espacio del comportamiento de las relaciones bajo estudio. Más precisamente esto implica que las formas funcionales y los parámetros no son homogéneos, sino que varían con la localización. Existen diferencias entre las zonas geográficas que son difíciles de incluir en las regresiones, por ejemplo el nivel de seguridad, el ruido, el riesgo, los cuales tienden a ser diferentes en cada barrio o sector y, como estas características tienden a estar correlacionadas, el término de error en cada área estará correlacionado con el de las áreas vecinas.

Este tipo de relaciones presentan retos metodológicos en la estimación; no obstante, recientes desarrollos estadísticos y de software permiten modelar mejor dichos procesos espaciales y plantear nuevas preguntas sobre la dimensión espacial de los procesos urbanos. Los desarrollos de sistemas de información geográfica y métodos estadísticos han permitido el mapeo de la información y el análisis espacial, facilitando su comunicación.

Desde la perspectiva metodológica el trabajo se realizó con la información referida al Municipio de Manizales Colombia, que se tiene en la Secretaria de Planeación Municipal, el Instituto Geográfico Agustín Codazzi (IGAC), Corporación Autónoma Regional de Caldas (CORPOCALDAS), Cámara de 
Comercio de Manizales y Cámara Colombiana de la Construcción (CAMACOL).

En dichas instituciones se encontraron los datos sobre las variables estructurales, de calidad y medioambientales que fueron usadas en el modelo. Se dispone de 67.802 predios residenciales de un total de 110.339 predios que tiene la ciudad, que se utilizaron en los análisis Econométricos. La información está geográficamente referenciada, la cual se presenta en un mapa donde se puede observar la distribución espacial de los datos usados en el modelo.

Se trata de hallar la ecuación del precio hedónico para la vivienda con estas observaciones para explicar el precio medio de las casas habitadas por propietarios e inquilinos, utilizando las interacciones espaciales.

Se utilizaron cinco variables que reúnen once atributos de la vivienda, entre las que figuran las características estructurales como:

1- El índice de construcción,que reúne las variables, área construida y superficie del lote.

2- El índice de calidad de la vivienda que considera los siguientes atributos:el destino de la vivienda, el estrato socioeconómico, el número de pisos de la vivienda, locales, baños y habitaciones. Los puntos por la calidad de la vivienda fueron asignados (según el IGAC).
Los temas ambientales consideran las otras tres variables, a saber:las zonas de tratamiento geotécnico en 453 puntos de la ciudad; el factor riesgo detectado en 28 sitios del municipio; el factor ladera ubicado en 99 espacios de este ente territorial. Finalmente se plantea la construcción de un modelo econométrico que muestre las bondades hedónicas y los efectos espaciales para fijar el avalúo catastral en la ciudad de Manizales con la posibilidad de ser replicado en otras ciudades que no han utilizado esta metodología, teniendo en cuenta que solo se encontró aplicación de precios hedónicos con análisis espaciales para la ciudad de Bogotá (Lozano, 2011), Medellín (Duque, 2011).

\section{REFERENTES TEÓRICOS}

Según Lever (2000), en un modelo de precios hedónicos, normalmente el proveedor de un bien o servicio enfrenta una demanda explícita por su producto, la cual determina en conjunto con la estructura de costos relevante, el comportamiento en el mercado de dicho proveedor. Cada bien y servicio, por su parte, está constituido por una serie de características o atributos que, en conjunto, configuran la unidad básica que es transada en el mercado. Dichos atributos, en la medida que son inevitablemente traspasados por el proveedor al consumidor al momento de efectuar éste la compra del bien, tienen la particularidad de afectar positiva o negativamente el precio de éste, dependiendo de la valoración que el 
demandante mantenga por cada uno de estos atributos. De este modo, se generan mercados implícitos por cada atributo, cuyas demandas y ofertas, no obstante, no son observables en forma directa.

En la mayoría de los casos, conocer las demandas implícitas por las características que componen un bien o servicio carece de relevancia, especialmente en aquellos mercados en que dichas características, cuantitativa y cualitativamente, se reflejan en forma relativamente transparente en los precios. En mercados más complejos, como el de los bienes raíces, el conocimiento de las demandas o los "precio sombra" de cada atributo cobra especial interés, fundamentalmente por la alta heterogeneidad de los atributos observados, su fácil diferenciación y el alto valor relativo de este tipo de bienes.

En tal sentido, la teoría de precios hedónicos constituye un significativo avance metodológico en la modelación de mercados implícitos por atributos, proporcionando técnicas econométricas para la obtención de precios y demandas implícitas a partir de la medición del precio del bien compuesto y de la forma en que se efectúa la "mezcla" de atributos que lo compone.

De esta manera, el valor de un bien raíz no sólo está determinado por sus características estrictamente residenciales, comerciales o industriales, sino también por los complejos procesos de inversión, especulación y arbitraje que tienen lugar con el crecimiento y desarrollo urbano de las ciudades, con la congestión de las áreas urbanas inducida por el mayor poblamiento y el crecimiento de la edificación, y con las políticas de regulación urbana que implementa la autoridad (Lever, 2000), al lado de los factores como acumulación de capital que contribuyen al desarrollo de la denominada competitividad sistémica del territorio (Ramírez, 2006).

Uno de los factores que mueve a las firmas a buscar vecindades con otras similares, es el aprovechamiento de los desbordamientos tecnológicos que se desatan cuando un conjunto de empresas tiene proximidad en el espacio. Los flujos de información que son propiciados en dichas concentraciones productivas se reflejan en mejoras en productividady eficiencia. (Arias, 2012)

De esta manera, la teoría de precios hedónicos pretende explicar el valor de un bien raíz, entendido como un conjunto de atributos (superficie, aptitud de uso del suelo, calidad de la construcción, diseño interior y exterior, áreas verdes, ubicación, características del vecindario) en función de cada uno de ellos, obteniendo sus respectivas valoraciones $\mathrm{y}$, por ende, demandas implícitas. En otras palabras, la teoría permite identificar la importancia relativa de cada atributo en el valor asignado por el mercado a un bien raíz, mediante lo cual es posible determinar cómo cambiará dicho valor al variar la cantidad y calidad en que se encuentra presente cada uno de estos atributos, y consecuentemente, predecir precios. 
La metodología utilizada consiste en construir un modelo econométrico que explicite la relación funcional entre el precio del bien raíz y sus respectivas características, dotarlo de información estadística y regresionarlo, procesando luego los resultados de manera de estimar la valoración implícita por cada atributo. (Lever, 2000).

El conceptual, permite utilizar el modelo de precios hedónicos para observar el impacto que tienen las características y atributos sobre el precio de un bien y, por consiguiente, construir la demanda por estos atributos. Esto sugiere que un bien o servicio puede tener multiatributos que satisfacen varias necesidades al mismo tiempo (Mendieta, 2001).

A manera de ejemplo se puede establecer, lo siguiente: Si la casa A: Está ubicada en un sitio con tratamiento de ladera, la casa B: tiene una mejor localización libre del peligro de ladera y en todo lo demás, las casas son idénticas. Cada casa tiene su precio, $\mathrm{P}_{\mathrm{A}}$ y $\mathrm{P}_{\mathrm{B}}$. La diferencia entre estos dos precios se explica porque refleja una disposición a pagar DAP por el tratamiento de ladera. Entonces:

$$
\mathrm{P}_{\mathrm{B}}-\mathrm{P}_{\mathrm{A}}=\mathrm{DAP} \text { por el riesgo existente }
$$

[1] (Mendieta, 2001).

Esta misma ecuación se puede aplicar para el atributo ambiental que tienen los bienes y servicios que se transan en el mercado, para hallar su precio, haciendo la diferencia entre los precios de mercado de dos bienes o servicios que sólo se diferencian en el atributo ambiental.

Este método de precios hedónicos permite valorar intangibles y bienes o servicios no mercadeables como el medio ambiente, que se ha utilizado tantas veces en bienes raíces, mercados laborales, mercado de autos, entre otros (Mendieta, 2001). En general, externalidades positivas aumentan la disponibilidad de pago por una vivienda. Así, el consumidor paga por los beneficios externos que entregan el medio ambiente o calidad de una vivienda y deja de pagar por los costos externos o externalidades negativas.

La discusión teórica se interesa por conocer las contribuciones de algunas de las características de la vivienda al avalúo y precio del bien compuesto, utilizando técnicas econométricas para obtener las funciones hedónicas que tienen como regresores los atributos de la vivienda como un todo y único bien. La teoría indica que entre las muchas características estructurales o físicas que puede tener una vivienda se encuentran las siguientes:

Superficie en metros cuadrados construidos, el tamaño del lote, aptitud de uso del suelo, aspectos de arquitectura y diseño interior, equipamiento interior, la calidad de los materiales, áreas comunes, número de cuartos, tamaño promedio de los cuartos, número de baños, número de alcobas, número de pisos, número de sanitarios, chimeneas, garajes, edad y año 
de construcción, pisos y techos, sótanos (Asqueta, 1994), patio de ropas, redes inteligentes, terrazas, ascensor, altitud, visibilidad, confort, calidad de la vivienda. Estos atributos se pueden tener en cuenta para valorar las viviendas, agrupándolas de acuerdo a la disponibilidad de información georeferenciada (Valencia, 2012).

Todas estas características estructurales se pueden llamar Sh, que formalmente se representa en el modelo hedónico por:

$$
\mathrm{Sh}=\mathrm{Sh}_{1}, \ldots \ldots \ldots, \mathrm{Shn}
$$

[2] (Asqueta, 1994)

Otros atributos serían los del vecindario como: estrato socioeconómico, tipo de residentes, centros comerciales, escuelas, colegios, centros recreativos, centros deportivos, tipo de calle, iglesias, nivel de ingreso, porcentaje de desempleo, porcentaje de familias con niños, densidad de la población, densidad de viviendas, seguridad, población mayor de 60 años, familias sin carros y con más de dos carros, tiendas, accesibilidad a centros de importancia, distancia a las autopistas o avenidas, localización del inmueble dentro del plan de ordenamiento territorial POT de la ciudad de Manizales (POT, 2007).

Otros factores que pueden influir en el precio de la vivienda son la ubicación del bien raíz en área residencial o industrial o comercial, distancia geográfica, densidad de la construcción, tipos de actividades y usos permitidos del suelo, proximidad al empleo, medios de transporte, tráfico vehicular y de transeúntes (Asqueta, 1994), equipamiento externo, servicios e infraestructura que recibe el inmueble como redes de acueducto, alcantarillado, electricidad, gas domiciliario, telefonía fija, internet, televisión, iluminación de calles, conjunto cerrado (Valencia, 2012).

La representación para el modelo de las anteriores características es:

$$
\mathrm{Nh}=\mathrm{Nh}_{1}, \ldots \ldots \ldots . . \mathrm{Nhm}
$$

[3] (Asqueta, 1994)

Las características ambientales que pueden ser externalidades positivas o negativas como las siguientes serían otro vector a considerar: el entorno, brillo solar, la calidad del aire y del agua, nivel de ruido, paisaje, zonas verdes, parques, vistas, partículas suspendidas totales, $\mathrm{SO}_{\mathrm{x}}, \mathrm{CO}_{\mathrm{x}}$, $\mathrm{NO}_{x}$, posibilidades de riesgo de avalanchas, erosión inundación; Áreas de tratamiento geotécnico; recolección, transporte y disposición final de las basuras; los malos olores, cercanía de acuíferos, gasoductos, oleoductos, quebradas y ríos, humedad, contaminación visual, tratamiento de ladera, etc. (Valencia, 2012). Su función sería:

$$
\mathrm{Qh}=\mathrm{Qh}_{1}, \ldots \ldots \ldots \ldots \mathrm{Qhq}
$$

\section{Expresión del modelo teórico}

Para determinar la relación entre el precio estadístico de compra-venta del bien que tiene mercado y una serie de variables 
que explican dicho precio, entre las cuales está la variable ambiental, según expresiones 2, 3 y 4 . Se tiene una función del tipo:

$\mathrm{P}=\mathrm{f}\left(\mathrm{Sh}_{1} \ldots \mathrm{Shn}, \mathrm{Nh}_{1} \ldots \mathrm{Nhm}, \mathrm{Qh}_{1} \ldots \mathrm{Qhq}\right)$

[5] (Asqueta, 1994)

Donde $\mathrm{P}$ es el precio estadístico de compra-venta del bien con mercado y Sh, $\mathrm{Nh} y$ Qh son los atributos y características que determinan el precio de la vivienda, donde $Q h$ es la variable ambiental que no tiene mercado. Si se procede estadísticamente, de la función 5 se puede calcular el deseo marginal a pagar "D", que será igual a la derivada parcial del precio con respecto a la variable ambiental Qh:

$$
\mathrm{D}=\partial \mathrm{P} / \partial \mathrm{Qh}
$$

Obteniendo el deseo total a pagar a partir del deseo marginal a pagar, que en forma lineal podemos expresar:

$$
\begin{aligned}
& P_{l}=\beta_{0}+\beta_{i} S h_{l i}+\alpha_{j} N h_{l j}+\gamma_{k} Q h_{l k}+u \\
& \forall l:(1,2, \ldots n) ; \forall i:(1,2, \ldots n) \\
& \forall j=(1,2, \ldots n) ; \forall k=(1,2, \ldots n)
\end{aligned}
$$

Donde $S h_{l i}$ : es la matriz ${ }_{1 * \mathrm{i}}$ que representa los i- atributos de la muestra $1 ; N h_{l j}$ : es la matriz $_{1 * j}$ que representa los j-atributos de la muestra 1; $Q h_{l k}$ : es la matriz ${ }_{1 * \mathrm{k}}$ que representa los k-atributos de la muestra 1

De esta expresión se deduce que

$$
\mathrm{D}=\partial \mathrm{P} / \partial \mathrm{Qh}=\gamma_{k}
$$

O sea, que $\gamma_{k}$ es constante y no depende del nivel alcanzado por la variable ambiental. Además, $\gamma_{k}$ informa cuánto varía el precio residencial cuando la variable ambiental varía en forma marginal, dejando lo demás constante.

Los fundamentos teóricos de este procedimiento para obtener los determinantes de precios de la vivienda se encuentran en Rosen (1974). Tomando como base la hipótesis hedónica de que los bienes son valuados por la utilidad que brindan sus atributos o características.

En un marco histórico, la mayoría de los autores sitúan el origen de la metodología de precios hedónicos (MPH) en los trabajos realizados por Court (1939) para la determinación de precios en el mercado automovilístico. No obstante, otros autores citados por Caridad (2008) como Colwell y Dillmore, señalan que el verdadero origen de los modelos hedónicos es preciso situarlo diecisiete años antes", en 1922, cuando (Hass, 1922) aplica esta metodología al cálculo de precios de la tierra de cultivo; Wallace (1926) continúa esta misma línea de investigación en Iowa. También se observa una aplicación de la MPH en el estudio de la calidad de las legumbres realizada por Waught (1929). Los estudios posteriores sobre MPH son atribuibles a Lancaster (1966) quien desarrolla la denominada nueva teoría del consumidor, según la cual la utilidad se deriva de las características de los bienes y no de los bienes en sí mismos. 
Otros referentes teóricos indican que la primera aplicación de esta metodología al mercado de la vivienda se halló en los trabajos de Ridker, (1967) los cuales aportaron evidencia empírica cuando analizaron para St. Louis, Estados Unidos, el efecto de la contaminación del aire sobre el precio de mercado de las viviendas, así como las otras características propias de los inmuebles y su vecindario.

Pero es Rosen (1974) el primero en proporcionar un tratamiento formal y unificado del modelo teórico de los mercados implícitos subyacentes en el modelo de precios hedónicos MPH. A partir de este momento, el modelo desarrollado por Rosen ha llegado a ser generalmente aceptado como el paradigma del enfoque hedónico.

El modelo teórico en que se basa el estudio de los precios hedónicos desarrollado por Rosen (1974) plantea que los bienes son valorados por la utilidad que brindan sus atributos o características. De este modo, los precios implícitos o precios sombra de los atributos son revelados a los agentes económicos a partir de los precios observados de los productos diferenciados y de las cantidades y calidades de los atributos asociados a ellos. Después, Rosen enunció formalmente un MPH en dos etapas para obtener precios (primera etapa) y demandas (segunda etapa) implícitas para cada atributo o característica (Rosen, 1974). Así mismo Freeman, (1979) facilitó la primera justificación teórica para la aplicación de esta metodología al mercado de la vivienda.

\section{Aplicaciones de las teorías hedónicas}

Un ejemplo clásico sobre la demanda de calidad ambiental fue hecho por Rubinfeld y Harrison (1978) para la ciudad de Boston USA, midiendo los beneficios de una propuesta de regulación ambiental para justificar su costo. Concretamente se trataba de imponer una fuerte regulación a las emisiones de óxidos de nitrógeno de los autos. Este modelo sirvió de base para construir y aplicar dicha metodología en este trabajo.

Rubinfeld y Harrison (1978) hallaron la ecuación del precio hedónico para la vivienda con 506 observaciones para explicar el precio medio de las casas habitadas por sus propietarios MEDV, utilizando, el censo decenal de población estadounidense. Emplearon trece variables, entre las que figuran, las características estructurales como los cuartos promedios por casa habitada por su propietario RM y características del vecindario como la tasa de criminalidad o delincuencia per cápita CRIM, otras, de accesibilidad como la distancia ponderada a cinco centros de trabajo DIS y un atributo o mejor un daño ambiental como la concentración anual promedio de óxido de nitrógeno NOX partes por diez millones por ciudad. 
También tuvieron en cuenta la tasa de impuestos por USD 10.000 sobre el valor total de la propiedad TAX; tasa de alumnos por profesor PTRATIO; proporción de negros $\mathrm{B}$; valores porcentuales de la población de menor estrato LSTAT; índice de accesibilidad a las autopistas radiales por ciudad RAD; proporción de viviendas ocupadas por sus dueños, construidas antes de 1940 AGE; variable dummy que vale uno si bordea el Río Charles y cero en otro caso CHAS; proporción de industrias por acre INDUS; proporción de casas con lotes sobre los 25.000 piecuadrado por ciudad ZN.

Este estudio probó que los beneficios por la limpieza del aire que tendría una familia promedio estaba entre un valor de $\$ 59$ y \$118 dólares por año y concluyeron que con la regulación se podía reducir la contaminación de autos con un beneficio esperado de $\$ 100$ dólares para la familia típica (Kolstad, 2000).

En Guatemala en un trabajo realizado por Díaz, Vanegas y Camacho (2014), se estima el valor de las tierras rurales del país con objeto de facilitar de forma objetiva los procesos de financiamiento de fincas, para el establecimiento de comunidades agrarias sostenibles. En dicha investigación se analizaron mediante trabajo de campo 64 fincas para estimar relaciones entre el precio por unidad de área y una serie de variables independientes tanto cuantitativas como cualitativas mediante análisis de regresión múltiple. Con significancia del $5 \%$ se concluyen que las variables que ejercen mayor efecto sobre el valor de las tierras rurales son: la región natural donde están ubicadas las fincas; el área; la distancia a la cabecera departamental y la infraestructura vial de acceso (con o sin asfalto). Se determinaron modelos estadísticos de tipo logarítmico de la forma: $\mathrm{LN}$ (Precio ha $\left.^{-1}\right)=\beta_{0}+\beta_{1} \mathrm{LN}$ (área) $+\beta_{2} \mathrm{LN}$ (distancia cabecera departamental).

En Colombia se hizo en el 2011 un estudio con aplicaciones de precios hedónicos y variables espaciales para la vivienda en la ciudad de Bogotá con una buena capacidad predictiva. Los propósitos de este trabajo fueron fiscales y se centraron en el modelo basado en la heterogeneidad espacial, siendo pionero en Colombia. Se concluyó que la inclusión de las variables espaciales predice mejor que los modelos tradicionales (Lozano, 2011).

De la misma forma, Galvis y Carrillo (2013) realizaron la formulación de un índice que cuantifique los diferenciales de precios de vivienda entre regiones en Colombia. Para este efecto se usaron el método de emparejamiento PSM (Propensity Score Matching), con el que se pretendían establecer comparaciones homogéneas entre los inmuebles de cada ciudad al evaluar el diferencial de precios. Además, realizaron dos ejercicios adicionales, que consisten en: (i) comparar las viviendas según rangos de precios (bajo, medio y alto) entre las ciudades, empleando regresiones hedónicas por cuartiles, y (ii) examinar cómo cambia la diferencia 
promedio de precios cuando varía la canasta de características de la unidad habitacional. Entre los principales resultados se encuentra que Bogotá tiene el precio más alto de vivienda estándar, seguida de Cartagena y Villavicencio. En términos prácticos, las brechas de precios halladas son importantes y alcanzan cifras cercanas al 30\%. Dichas brechas no son homogéneas entre diferentes clases de vivienda estándar, ni entre rangos del precio

Según el planteamiento de Revollo (2009), a través de un modelo de precios hedónicos se determina qué variables estructurales y del entorno afectan el precio de la vivienda en Bogotá de localidades pobres y ricas. Asimismo se concluye que la inversión en obras públicas puede afectar positiva o negativamente el nivel de precios por vía indirecta a través del cambio en el uso de la tierra y dependiendo de la localidad donde sea ejecutada.

Otro estudio realizado en Colombia usando modelos econométricos tradicionales, de la econometría espacial y de regresión ponderada geográficamente, para analizar y comparar a la luz de estos modelos la influencia que tiene en los precios de las viviendas la existencia de una estación del metro en San Javier ubicada en el centro occidente de la ciudad de Medellín, Colombia. El principal hallazgo en este estudio es que la presencia de la estación del metro tiene una influencia positiva en los precios de las viviendas localizadas en un radio de 600 metros alrededor de la estación; sin embargo, las viviendas cercanas a las vías de acceso del metro a la estación presentan un importante decremento en sus precios (Duque, 2011).

También se observa una aplicación en la ciudad de Manizales, Colombia,en un trabajo que aplica un método diseñado por el BID para el monitoreo de la calidad urbana que se basa en la combinación de dos enfoques: precios hedónicos y satisfacción con la vida. Esta combinación permite efectuar una valoración de los bienes públicos locales tanto desde el punto de vista del mercado como de la utilidad. Los resultados de la aplicación del método para la ciudad de Manizales, Colombia revelan que, aunque para algunos bienes públicos la valoración que efectúa el mercado resulta suficiente, para otros existe una valoración adicional representada en el bienestar que les aportan a los habitantes y que el mercado no logra capturar (Velásquez, 2011).

Además de la valorización de inmuebles, a partir de la aplicación de modelos hedónicos ha sido posible establecer efectos sobre la valorización de distintos tipos de bienes raíces ante la presencia de diversas externalidades. Lever (2000) determinó que en la ciudad de Sao Paulo la proximidad de una favela genera una desvalorización de un $19 \%$ en las viviendas cercanas, pero que dicha desvalorización disminuye en un $2 \%$ por cada 100 metros que se aleja la favela.

De la misma forma, en la localidad de Pirque, en Santiago de Chile, se estimaron desvalorizaciones de distinta 
magnitud en los terrenos afectados por el trazado de un gasoducto, dependiendo de la cercanía a éste. También en Sao Paulo, se calculó una valorización de un $12,6 \%$ para viviendas próximas a áreas verdes, resultado similar al descubierto en la V Región de Chile, donde se estimó una valorización de un $12,9 \%$ en desarrollos residenciales con más de un $10 \%$ de su superficie destinada a áreas verdes (Lever, 2000).

Ridker (1967) emplea la variable ingreso como proxi para las características de la propiedad y del vecindario no incluidas explícitamente en su modelo de precios de viviendas, y encuentran un efecto positivo; Witte (1974) dice que las viviendas son productos heterogéneos, por lo tanto, los diferentes precios a los que se transan no reflejan necesariamente diferencias en valoración monetaria, sino que pueden ser atribuidos a diferencias en sus características. Esta heterogeneidad se vuelve evidente cuando se comparan viviendas entre barrios o comunas, ya que es más factible que las viviendas encontradas en la base de datos sean muy diferentes. Por ejemplo, una proporción de la población tiene ingresos más altos que cualquier otro barrio y las viviendas asociadas a esos ingresos tienen características muy distintas y de mayor costo que en un sector de bajos ingresos. Por lo tanto, para efectuar comparaciones de costo de viviendas entre barrios es necesario corregir la heterogeneidad espacial de ellas.

Manning (1988) explica diferenciales de precios de terrenos entre ciudades de
Estados Unidos, por diferenciales de ingresos de los residentes. Peiser (1987), "concluye que vecindarios con mayores ingresos determinan mayores rentas al comercio circundante, lo que produce mayores precios de la tierra urbana en su período de desarrollo; Roback, (1982) utiliza la variable densidad poblacional como proxi para el nivel de urbanización del sector, encontrándole todos ellos coeficientes positivos.

Manning (1988), pese a advertir que mayor densidad poblacional está asociada a mayores índices de delincuencia y polución, encuentra empíricamente que tanto aumentos de densidad como mayores velocidades de crecimiento de la densidad, provocan aumentos en los precios de los bienes raíces; además explica el predominio de los efectos positivos por las mayores oportunidades económicas, culturales y sociales que induce la mayor densidad.

De la misma forma Diamond (1980) presenta estudios en distintas ciudades que identifican una gradiente de precios determinada por la distancia a los centros de negocios (central business district); Johnson (1987) descubre que viviendas alejadas de los centros de negocio pueden revertir la declinación de los precios si cuentan con buenas vías de acceso; $\mathrm{Li}$ (1980)" sostiene que se puede producir un exceso de cercanía al centro, cuando este genera congestión.

Palmquist (1984) anota que el efecto neto de usar los precios de venta incluyendo 
el valor de la renta es probablemente pequeño debido a otros efectos contrarios a la dirección del impuesto a la propiedad. Los datos sobre precios de ventas son más utilizados en la estimación de modelos hedónicos, mientras que los datos sobre renta son sólo aplicados en modelos de postura de renta.

La importancia de asumir la complementariedad débil ${ }^{1}$, resulta de hecho que las familias tienen una DAP positiva por calidad ambiental sólo si ellos actualmente viven en esta zona. Si la complementariedad débil no es un supuesto válido la estimación hedónica debería subestimar la disponibilidad a pagar. La distinción entre la percepción de las familias por calidad ambiental y la medición de la calidad ambiental actual es importante. Los estudios hedónicos asumen implícitamente que las familias pueden percibir las diferencias en calidad ambiental (Maller, 1977).

De la misma manera, la estructura de los precios hedónicos debería reflejar solamente la DAPde los hogares por un atributo en particular, si el nivel de medición de este atributo corresponde a lo percibido por el consumo de las familias. La estimación del precio de un atributo requiere la percepción de la calidad ambiental como una variable independiente (Harris, 1981).
Los problemas relacionados con la aplicación de modelos hedónicos son las imperfecciones de mercado, información imperfecta (faltante) y los problemas en la medición del error. Para las aplicaciones empíricas se supone que el mercado está en equilibrio y la oferta por viviendas es fija. Estos supuestos son válidos para el corto plazo pero no para el largo plazo. Por lo general, el mercado de la vivienda en el largo plazo no está en equilibrio (Cropper, 1981).

En este sentido, la falta de observación de los productos o las características de los agentes y los errores de medición pueden tener una gran influencia sobre la estimación hedónica (Kolstad, 2000).

\section{METODOLOGÍA}

\section{Análisis espacial}

En este trabajo se hace uso del análisis de regresión de corte transversal para determinar cuáles son los atributos relevantes y la importancia relativa de cada uno de ellos, mostrando la interacción espacial de los datos aprovechando la información georreferenciada. Se tiene en cuenta el planteamiento de Krugman (1997), según el cual, la nueva geografía económica NGE permite conectar y relacionar los efectos marginales que se

La complementariedad débil se presenta cuando se desconoce la relación que liga el precio de la vivienda con la cantidad del bien ambiental. Esta complementariedad débil supone que la utilidad marginal del bien ambiental se hace 0 cuando la cantidad demandada del bien de mercado es 0 , en otras palabras, existe complementariedad débil entre un bien privado y un bien ambiental, si la utilidad marginal que proporciona el bien ambiental (medida por la disposición marginal a pagar por una unidad adicional del mismo, su precio implícito) se hace 0 al dejar de consumir el bien privado. 
obtienen en el análisis hedónico con los efectos espaciales de vecindad como la imitación, los spillovers, las externalidades, y el contagio.

Este método se usóconsiderando que la econometría espacial facilita ensayar métodos globales y locales de análisis de autocorrelación espacial en las observaciones que se construyen y las variables que se utilizan. Con esto se pretendía evitar que la ausencia del análisis de las interacciones espaciales pueda sesgar los resultados e invalidar los test de significancia utilizados.

En este trabajo se tienen en cuenta los dos tipos de interacciones espaciales existentes: dependencia espacial o autocorrelación espacial y heterogeneidad, que se describen a continuación.

\section{Dependencia espacial o autoco- rrelación espacial}

La dependencia espacial se presenta cuando una de las variables explicativas asume valores similares a otras que están geográficamente cercanas, dando lugar al surgimiento de clústers. Si los valores altos están relacionados con altos precios en las viviendas vecinas, entonces la autocorrelación es positiva, y si los valores altos se corresponden con valores bajos, la autocorrelación es negativa. Esto se puede observar en el mercado de la vivienda, donde las casas costosas tienden a estar agrupadas al igual que las casas baratas. Esta autocorrelación espacial aparece por la existencia de una relación funcional entre lo que ocurre en un punto determinado del espacio y lo que ocurre en otro lugar(Moreno, 2000).

\section{Heterogeneidad espacial}

La otra interacción es la heterogeneidad espacial que muestra la inestabilidad estructural y la heteroscedasticidad en el espacio de los datos en estudio, que pueden variar de acuerdo con la localización como el paisaje, la contaminación, la tasa de criminalidad, las cuales tienden a ser diferentes en cada barrio o cuadra, lo cual, se puede resolver con técnicas econométricas existentes para series temporales.

La heterogeneidad espacial indica la presencia de diferencias sistemáticas en la ocurrencia de un fenómeno en distintas zonas geográficas, por ejemplo los precios del norte son distintos a los del sur o si las variables explicativas tienen un efecto distinto en ciertas regiones.

\section{Identificación de patrones espaciales}

Para este procedimiento se han presentado algunos estadísticos globales como los índices de Moran y la C de Geary, y otros locales como Lisa y Glisa (Moreno, 2000).

El índice de Moran es una medida de autocorrelación espacial que es análoga al coeficiente de correlación, cuyo valor está entre - 1 y 1 , significando autocorrelación espacial negativa fuerte con el $-1 \mathrm{y}$ autocorrelación positiva fuerte con el 1 . 
Antes de construir la Índice de Moran se debe definir la matriz de vecindad espacial. Este es uno de los temas operacionales cruciales en la econometría espacial, ya que se requiere expresar formalmente la estructura de dependencia espacial que va a ser incorporada al modelo. Esta matriz representa el patrón espacial entre las observaciones que llamaremos localizaciones (Anselin \& Getis, 1992). En el análisis exploratorio se define esta matriz.

\section{Formulación del índice de Moran}

Dado un conjunto de $\mathrm{n}$ localizaciones (Ai,.....An), se construye la matriz $W i j$, donde cada elemento de Wij, representa una medida de proximidad entre Ai y An. Entonces la Índice de Moran se define de la siguiente manera:

$$
I(d)=\frac{\sum_{i}^{n} \sum_{j \neq i}^{n} w_{i j}\left(x_{i}-\bar{x}\right)\left(x_{j}-\bar{x}\right)}{S^{2} \sum_{i}^{\mathrm{n}} \sum_{j \neq i}^{\mathrm{n}} w_{i j}}
$$

Donde

$$
S^{2}=\sum_{\mathrm{n}}^{1}\left(\mathrm{X}_{1}-\overline{\mathrm{X}}\right)^{2}
$$

Xi denota el valor observado de la población en la localización i, $\bar{x}$ es el promediode la $\mathrm{x}_{\mathrm{i}}$ sobre las localizaciones de $n$ y el Wij es la medida espacial del ponderador de proximidad. Es importante observar que los elementos de Wij son noestocásticos y exógenos al modelo. El estadístico I de Moran es positivo cuando los valores observados de las localizaciones a cierta distancia (d) tienden a ser similares, negativo cuando tienden a ser disímiles, y aproximadamente cero cuando los valores observados se distribuyen en forma aleatoria e independiente sobre el espacio.

Respecto a la distribución del contraste, cuando el tamaño muestral es suficientemente grande, el I de Moran estandarizado sigue una distribución asintótica normal. Si se asume que la distribución espacial de los datos es normal, la varianza del Moran para una muestra de tamaño $n$ puede ser calculada y por lo tanto también su significatividad estadística.

Este test tiene como hipótesis nula la no autocorrelación espacial entre los valores observados sobre las localizaciones y puede ser estimado con base en la siguiente variable aleatoria estandarizada:

$$
Z(d)=\frac{I(d)-E(I)}{\sqrt{\operatorname{Var}(I)}}
$$

Donde, E(I) y VAR(I) son la esperanza y la varianza de la I de Moran respectivamente (Sánchez, 2008).

\section{Población y datos}

El trabajo se lleva a cabo con información referida al municipio de Manizales suministrada por la Secretaría de Planeación Municipal, que, a su vez, la obtuvo del Instituto Geográfico Agustín Codazzi IGAC, la Corporación Autónoma Regional de Caldas CORPOCALDAS, la Cámara de Comercio de Manizales y la Cámara Colombiana de la Construcción CAMACOL. Esta información fue suministrada en diciembre de 2011 y 
resumida en una gran base de datos que se preparó con el formato Shape para poder ser validada por el software GEODA, suministrado por el Ph.D Luc Anselin.

En esta base de datos se encuentra la información sobre las variables estructurales, de calidad y medioambientales que se van a utilizar en el modelo. Se dispone de la información de 67.802 predios residenciales de un total de 110.339 predios que tiene la ciudad, que se van a utilizar en los análisis. La información está geográficamente referenciada, la cual se presentará en un mapa donde se puede observar la distribución espacial de los datos que se van a usar en este modelo, como se puede ver en el siguiente mapa:

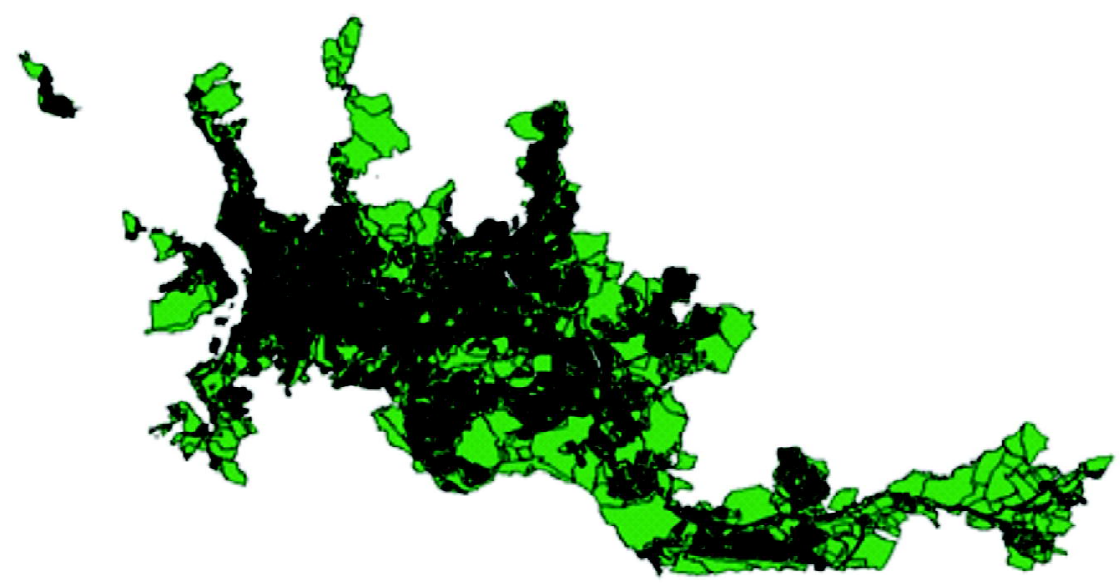

Mapa 1. Distribución espacial de los datos.

Fuente: construcción propia con la ayuda de Geoda.

Las partes obscuras señalan la cantidad de predios que se concentran en la distribución geoespacial, donde no se alcanza a detallar la figura de los predios, pero si se utiliza el zoom del programa Geoda, se puede apreciar mejor la localización de los predios, como se muestra en el siguiente mapa que seleccionó una parte de la ciudad y donde se puede observar que el tamaño de cada predio es proporcional a su extensión por metro cuadrado, los cuales se pueden ver en las formas rectangulares de los predios. 


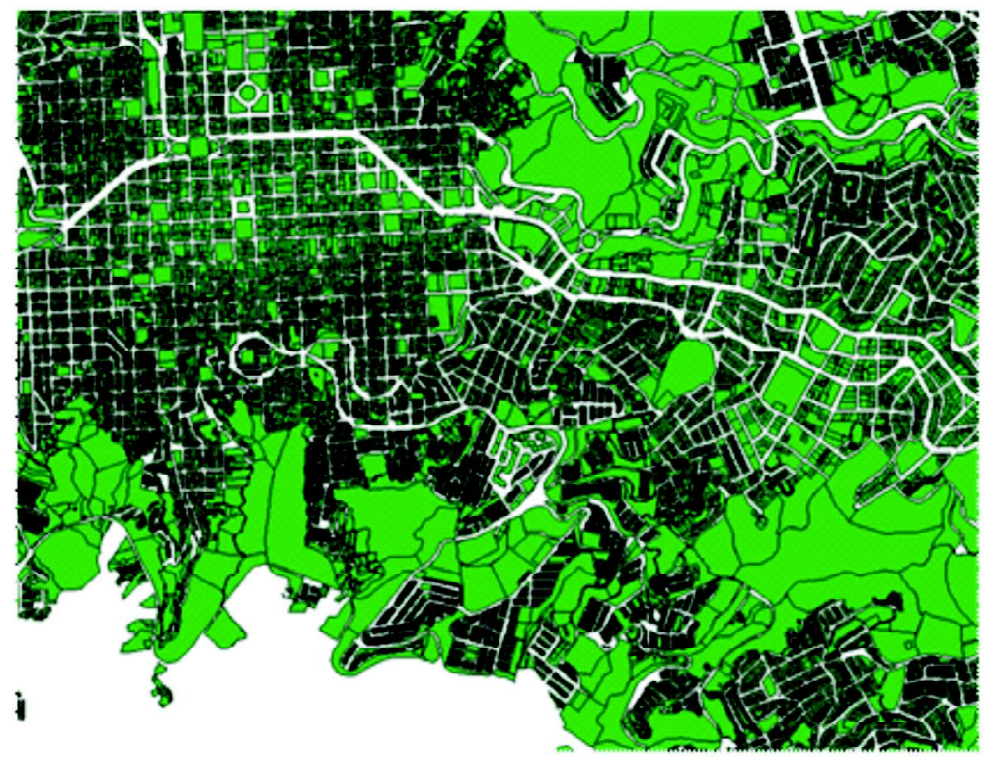

Mapa 2. Distribución espacial de datos en el centro.

Fuente: elaboración de los autores con ayuda de Geoda.

Con esta información se determina la ecuación del precio hedónico para la vivienda que explica los determinantes del avalúo por metro cuadrado de las casas habitadas por propietarios e inquilinos, en la ciudad de Manizales.

\section{Expresión del modelo}

$$
\begin{aligned}
& \mathrm{AVM}^{2}=\mathrm{f}(\mathrm{IC}, \text { PUNTAJE1, } \\
& \text { RIESGO, ATG, LADERA, Z) }
\end{aligned}
$$

La variable dependiente $\mathrm{AVM}^{2}$, corresponde al avalúo del bien raíz por metro cuadrado, el cual se asume está determinado por los argumentos de la función $\mathrm{f}$. Normalmente se tiende a privilegiar el uso de esta variable como el avalúo por metro cuadrado en lugar del avalúo total del inmueble, siguiendo la indicación teórica (corroborada por la experiencia empírica) de que la superficie de este ejerce una fuerte influencia como variable explicativa del valor del metro cuadrado.

Donde la variable dependiente es:

$\mathrm{AVM}^{2}$ que es el avalúo por metro cuadrado de la vivienda y las variables explicativas son:

IC es el índice de construcción igual al área construida sobre la superficie del predio

PUNTAJE1 es el índice de calidad de la vivienda 
RIESGO es el peligro de deslizamientos

ATG son áreas de tratamiento geotécnico con pantallas de concreto

LADERA es el peligro de estar cerca a este tipo de terreno

Z. son el conjunto de parámetrosque acompañan a cada atributo y que constituyen los precios implícitos (sombra) de cada característica del inmueble.

\section{Análisis exploratorio}

Para detectar patrones espaciales en este trabajo, se usó el estadístico índice de Moran (I de Moran) (Moran, 1948), que es análogo al coeficiente de correlación y sirve para medir la autocorrelación espacial. Para esto es necesario definir la matriz de ponderadores.

En la matriz de ponderadores espaciales utilizada para el cálculo de la I de Moran, se definieron como vecinos, aquellos predios que siguen el criterio de contigüidad de reina o queen, que establece, que serán vecinos del lote i todos los predios que comparten algún lado o vértice con i. Cuando se presentan algunos problemas de redundancias o rutas circulares en los predios vecinos que conducen a resultados espurios, se deben eliminar de las matrices de pesos espaciales estos inconvenientes para lograr una adecuada aproximación a la creación de retardos espaciales, lo cual se hace posible definiendo la contigüidad de órdenes superiores. Para este trabajo se determinó que dos predios i y j serán contiguos de segundo orden, si ambos están separados por un tercer predio que es contiguo de primer orden a ambos, encontrando 16 vecinos posibles al predio i, como se puede apreciar en el siguiente gráfico, donde el cuadro negro es la reina y se puede mover por todos los lados y los vértices hasta el segundo cuadro.

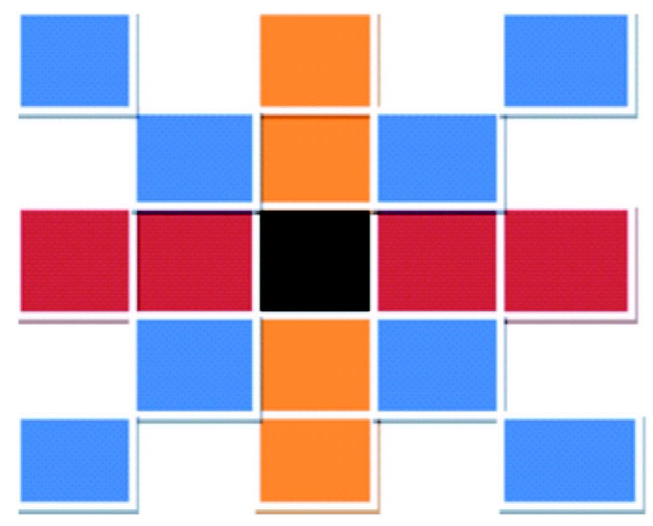

Gráfica 1.

Fuente: elaboración de los autores. 


\section{RESULTADOS}

\section{Análisis univariante delI de Moran para el logaritmo del avalúo por metro cuadrado}

Se trata de relacionar el avalúo de una vivienda en el eje $\mathrm{X}$ con el avalúo de las viviendas vecinas que se representan en el eje Y.

En la Gráfica 2, el índice de Moran presenta un valor alto de 0,6327 que muestra la existencia de una correlación espacial positiva y fuerte entre el logaritmo (log.) del avalúo por metro cuadrado de los predios LNAVM $^{2}$ y el logaritmo del avalúo por metro cuadrado de los predios vecinos W-LNAVM ${ }^{2}$, indicando con esto, que los predios más costosos tienden a situarse cerca de los predios de mayor valor y los predios de menor valor tienden a situarse cerca de los más baratos, sin embargo, quedan algunos datos en los cuadrantes II y IV, que no permiten presentar un índice de Moran más elevado, que muestre mayor similitud entre los predios observados con este criterio de vecindad utilizado.

A continuación se presenta una tabla que resume el análisis espacial global de las cinco variables explicativas y la variable dependiente. Se presenta el I de Moran con su correspondiente significatividad:

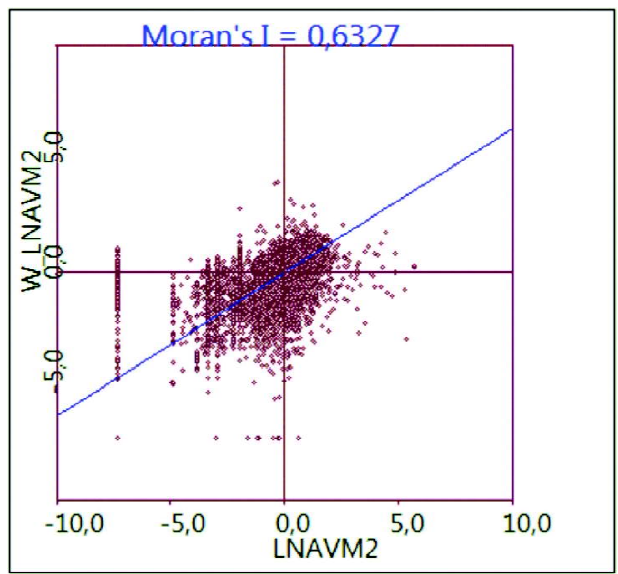

I: 0,6327P-Value: 0,002 Sd: 0,0027

\section{Gráfica 2.}

Fuente: elaboración de los autores con ayuda de Geoda.

Tabla 2. Análisis univariante de las variables utilizadas en el modelo

\begin{tabular}{|l|c|c|c|}
\hline Variables & Índice de Morán & Desviación Standar & P Seudo P-Value \\
\hline LNavalúo por M2 & 0,6327 & 0,0027 & 0,002 \\
LNíndice de construcción & 0,3617 & 0,0025 & 0,002 \\
Riesgo: 1=riesgo & 0,7997 & 0,0025 & 0,002 \\
Ladera 1=ladera & 0,7398 & 0,0027 & 0,002 \\
ATG: 1=ATG & 0,4985 & 0,0026 & 0,002 \\
LN índice calidad de la vivienda & 0,4905 & 0,0026 & 0,002 \\
\hline
\end{tabular}

Fuente: elaboración de los autores. 
El mismo análisis univariante realizado para la variable dependiente con base en el logaritmo del avalúo por metro cuadrado se puede hacer para las demás variables. Por ejemplo, el índice de construcción presenta un índice de morán de 0,3617, que muestra la existencia de una correlación espacial positiva y débil entre los índices de construcción de las viviendas, es decir que pueden haber viviendas de bajo índice de construcción con vecinos de alto índice de construcción.

La variable riesgo fue la que mejor correlación registró en este análisis global, marcando un índice de moran de 0,7997, indicando una correlación espacial positiva y fuerte entre las viviendas con riesgo de deslizamientos o sea que las casas con este riesgo tienen vecinos con el mismo problema. Es importante marcar que el índice de Morán es significativo al 0,2\% para todas las variables analizadas, lo que indica que hay una buena autocorrelación espacial entre los valores observados.

A continuación se describe la parte del modelo que se conoce como regresión geográficamente ponderada (GWR) que busca analizar la no estacionariedad de los datos. Esta técnica hace posible explorar si la asociación entre el valor de los predios y sus variables explicativas es constante en toda la región o si es posible identificar variaciones por zona.

\section{Análisis espacial local Lisa}

Estos análisis generalmente se realizan sobre los mapas que genera Geoda tanto para los análisis espaciales (colores rojo, azul, lila y rosado), como para el mapa que muestra la significancia de las variables (diferentes tonos de color verde). Hacer el análisis espacial Local LISA Univariante del LNAVM $^{2}$ con el avalúo del vecino (W-LnAVM ${ }^{2}$ ) que se puede relacionar en la siguiente mapa $\mathrm{N}^{\circ}$ 3 , pero que dada la cantidad de 67.802 predios, no se alcanza a visualizar plenamente los colores que identifican las relaciones espaciales. Para resolver este problema se puede hacer un zoom que amplía con más detalles los predios y los colores, tanto en el análisis espacial local, como en el mapa que muestra el grado de significancia. El siguiente mapa muestra el análisis espacial local LISA de la variable LNAVM ${ }^{2}$.

El color rojo (High-high) quiere decir que los predios de alto valor se ubican cerca de los predios costosos de los vecinos como se observa en el centro de la ciudad.

El color azul (Low-Low) indica que los predios de bajo costo se localizan cerca de los lotes baratos como los que se ven de color azul en el mapa.

El color lila (Low-High) muestra los predios de bajo costo rodeados de lotes vecinos costosos.

El color rosado (High-Low) referencia los lotes costosos que están rodeados de lotes baratos. 


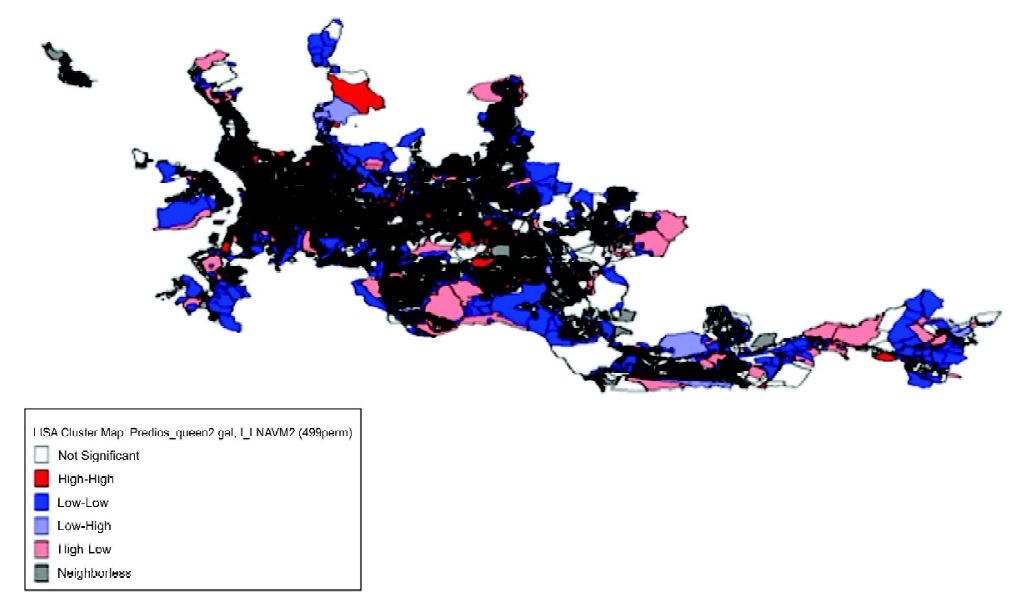

Mapa 3. Análisis espacial local LISA de la variable LNAVM² Fuente: elaboración de los autores con base en datos del IGAC.

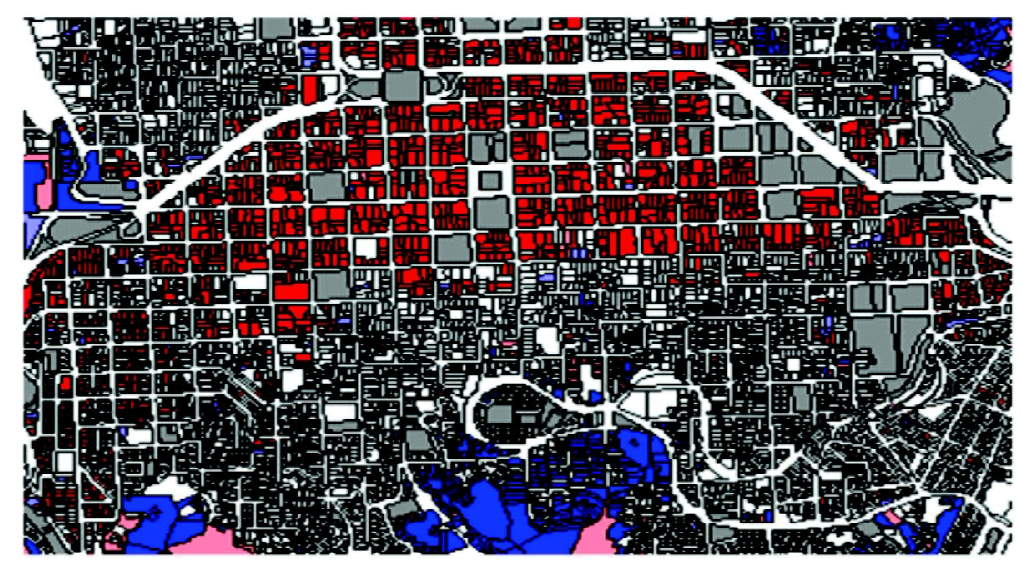

Mapa 4. Análisis espacial lisa de LNAVM2 sector centro ampliado. Fuente: elaboración de los autores con base en datos del IGAC.

En esta sección de la ciudad que va desde el parque Olaya hasta el parque Fundadores se puede ver que los mayores avalúos de los predios ocupados por viviendas y negocios dedicados al comercio y servicios se ubican cerca de los otros predios costosos. Este fenómeno espacial se puede observar entre la carrera 24 y la avenida del centro desde la calle 14 hasta la calle 33 . Los puntos de color gris corresponden a los predios ocupados por parques, iglesias, 
instituciones públicas como la alcaldía, la gobernación, viaductos y otros predios que no son significantes en el análisis Lisa.

Las zonas azules Low-Low localizadas entre las carreras 27 y 33 que van desde las calles 20 hasta la 27 muestran los avalúos bajos de los predios que se ubican cerca de lotes baratos con un alto grado de significancia, según el análisis siguiente.

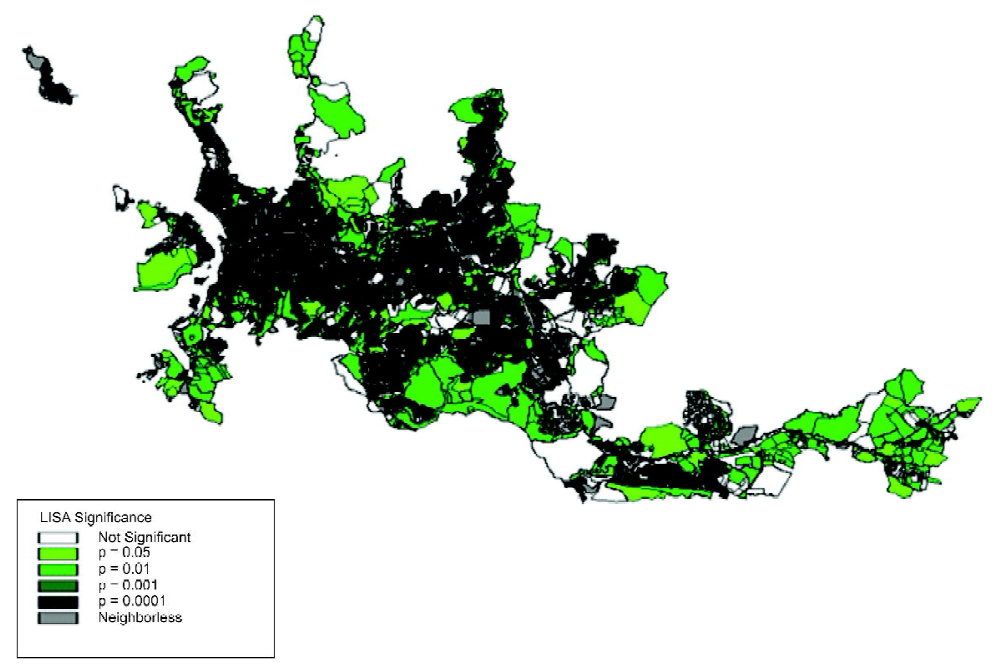

Mapa 5. Grado de significancia representado en el mapa lisa univariante del LNAVM²

Fuente: elaboración de los autores con base en datos del IGAC.

Nuevamente la cantidad concentrada de datos no deja ver el tono de los colores verdes, lo que exige utilizar el zoom del programa para ampliar el sector central de la ciudad.

El color verde claro indica que los lotes ubicados en esta zona son significativos al $5 \%$.
La zona color verde es significativa al $1 \%$, el sector verde menos obscuro es significativo al $0,1 \%$ y la zona con el verde más obscuro es la más significativa de todas con un $0,01 \%$.

El mapa 6 del sector centro ampliado, registra mejor el grado de significancia que el mapa 5, como se puede ver a continuación: 


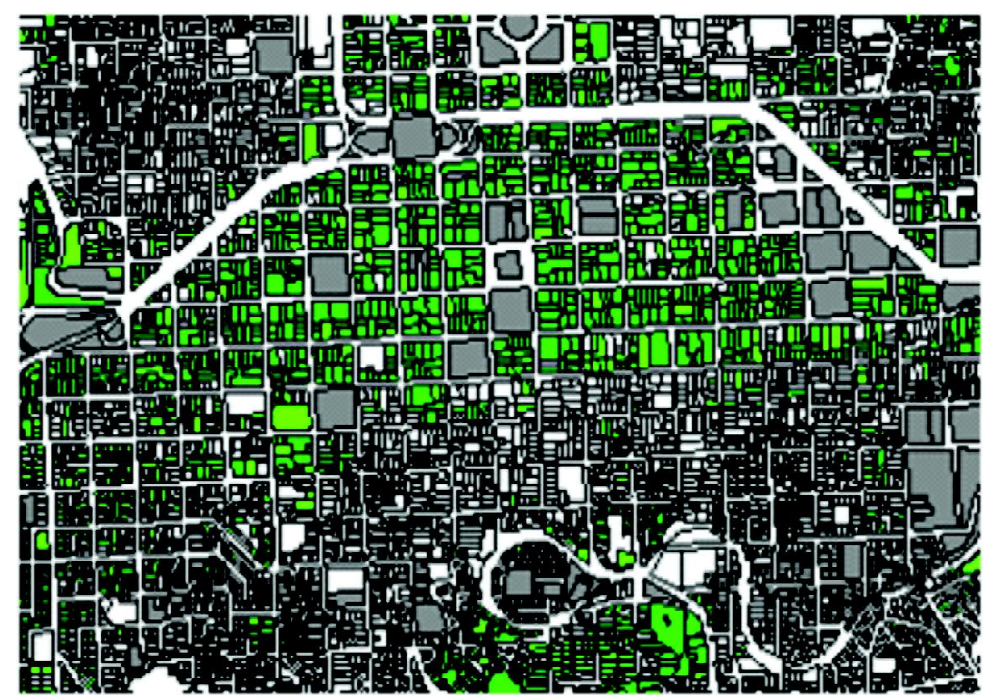

Mapa 6. Grado de significancia Lisa del LNAVM² sector centro. Sector: parque Olaya a Fundadores.

Fuente: elaboración de los autores con ayuda de sotware GEODA y con base en datos del IGAC.

Aquí se ve que los predios de alto valor se ubican cerca de los predios costosos de los vecinos HIGH-HIGH (color rojo mapa 4) con un grado de significancia de $\mathrm{P}=0,01$ (color verde mapa 6).

Los puntos de color azul indican que los predios de bajo costo se ubican cerca a los vecinos que tienen predios baratos LOW-LOW con un grado de significancia de $\mathrm{P}=0,01$, mostrando algo parecido a una clusterización de los predios baratos (mapa verde).

Los predios de bajo costo con vecinos que tienen predios caros LOW-HIGH están esparcidos por la parte central de la ciudad.

\section{Análisis exploratorio de la variable ambiental Ladera}

Se comienza este estudio con un análisis espacial univariante, relacionando las viviendas que tienen esta amenaza de ladera con las viviendas vecinas que también la tienen.

Este análisis global muestra una relación espacial positiva y fuerte del Índice de Moran igual a 0,7398 en un análisis univariante de la variable ambiental ladera indica que elcriterio de contigüidad de la Queen de segundo orden es relevante en el análisis espacial, mostrando una buena autocorrelación espacial. 


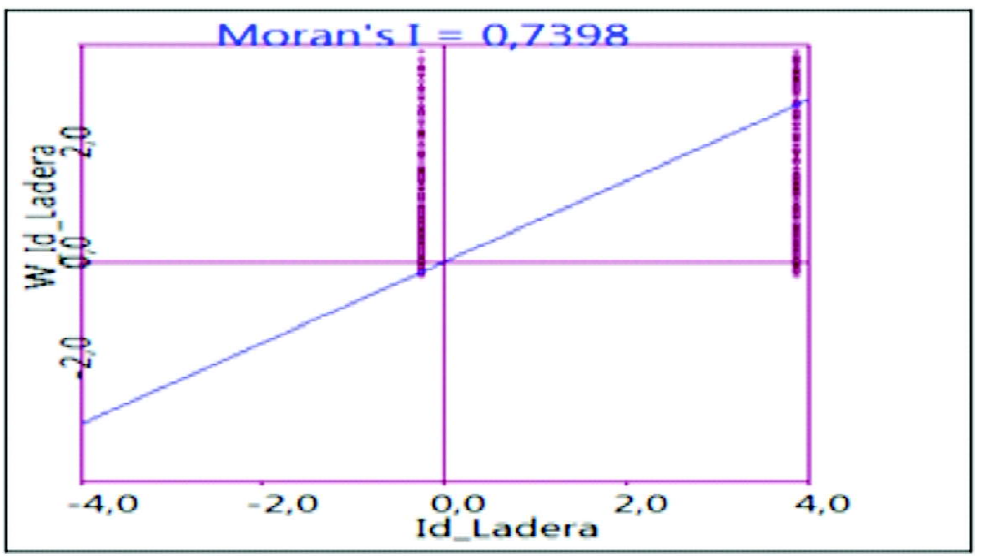

P-value: 0,002 I:0,7398Sd: 0,0027 Permut: 499

Gráfica 3

Fuente: elaboración de los autores.

\section{Análisis lisa de ladera}

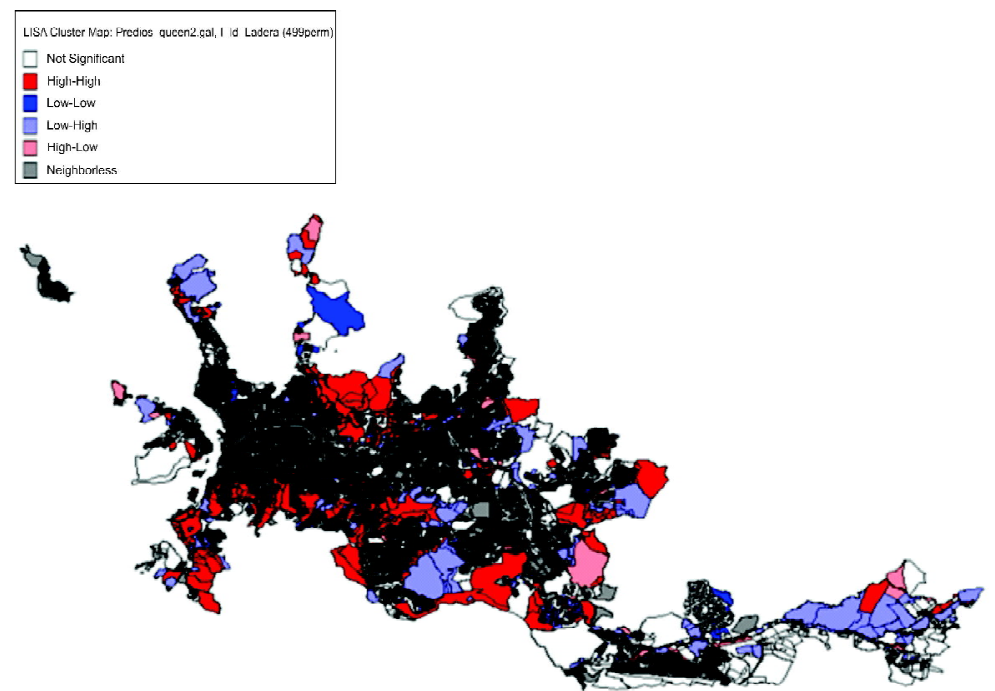

Mapa 7. Análisis espacial lisa de la variable ladera.

Fuente: elaboración de los autores con base en datos del IGAC. 
El color rojo (High-High) indica que las viviendas con esta amenaza alta se agrupan alrededor de la ladera o sea que los vecinos también tienen este peligro.

El color azul (Low-Low) muestra la baja amenaza de las viviendas con vecinas que tampoco tienen este peligro. El lila (LowHigh) tienen baja amenaza, pero los vecinos están en peligro y el color rosado (High-Low) indican amenaza alta con vecinos que no la tienen.
El siguiente mapa con zonas de color verde enseña el grado de significancia que tiene la variable Ladera en este análisis espacial univariante local

La intensidad del color verde que va desde el verde claro con una menor significancia de $\mathrm{P}=0,05$ hasta el verde obscuro con la mayor significancia de $\mathrm{P}=0,0001$.

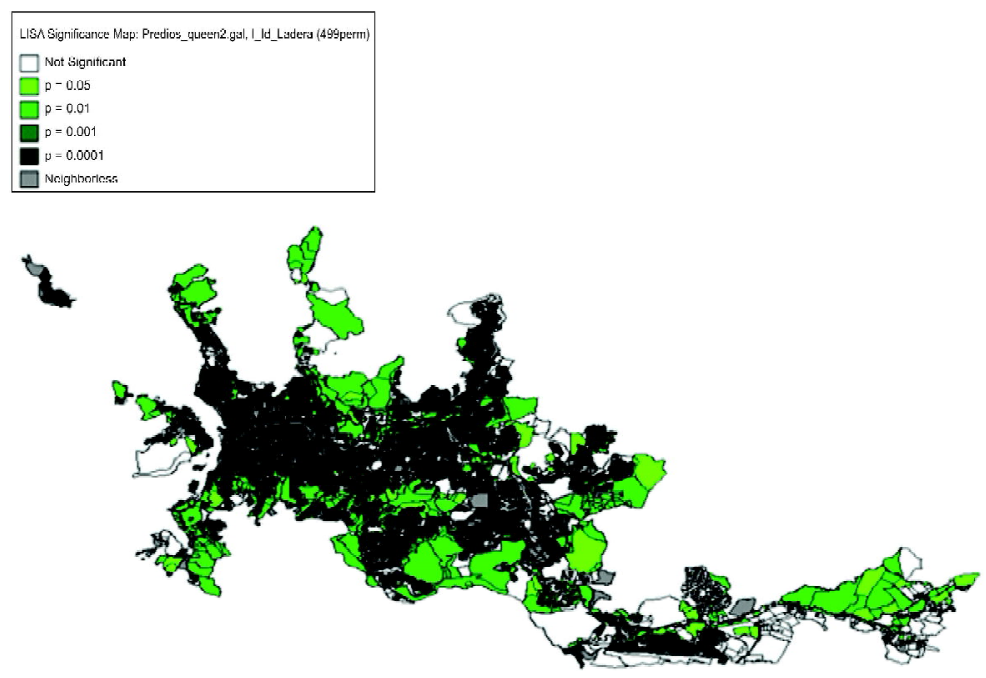

Mapa 8. Grado de significancia lisa de ladera

Fuente: elaboración de los autores con ayuda de sotware GEODA y con base en datos del IGAC.

El grado de significancia de color verde (mapa 8), se ubica en la correspondiente zona del color que muestra el mapa $7 \mathrm{y}$ que están afectados por las 99 laderas de la ciudad. Este mismo análisis univariante se puede observar en las demás variables que se registran en los anexos 4, 5, 6 y 7 .
Por ejemplo, si se analiza el mapa del anexo 4, se observa que los predios con bajo índice de construcción se localizan alrededor de otros con IC similares y que corresponden a la gran mayoría de predios esparcidos por toda la ciudad (color azul), lo que evidencia que en esta ciudad predominan las 
construcciones de 1 y 2 pisos, mostrando un desarrollo horizontal, sin embargo, en los últimos años se viene cambiando esta tendencia por un crecimiento vertical de las construcciones (Low-High).

El color rojo que se identifica como HighHigh, indica que los predios con los más altos IC se localizan al lado de vecinos que construyen verticalmente, especial-mente, en el centro de la ciudad. Otros outliers (puntos fuera del clúster) de color rojo se ven en diferentes sitios de la ciudad.

De este análisis univariante de las variables se pasa al análisis multivariante, donde efectivamente se relaciona cada una de las variables explicativas con la variable dependiente $\mathrm{LNAVM}^{2}$. La Tabla 3 resume los índices de Moran de estas relaciones con su grado de significancia.

Uno de los intereses de este trabajo es involucrar la variable ambiental en las interacciones espaciales, en este caso, se trata de observar el comportamiento de la variable LADERA en el eje X con el avalúo por metro cuadrado de los predios vecinos W-LNAVM ${ }^{2}$ en el eje $\mathrm{Y}$

En la siguiente Gráfica 4 se muestra esta relación que se explica a continuación.

\section{Análisis espacial multivariante global}

Tabla 3. Análisis de la índice de Moran multivariante

\begin{tabular}{|l|c|c|c|}
\hline Variables & Índice de Morán & Desviación Standar & PSeudo P-Value \\
\hline LNAVM'2-LNIC & 0,1450 & 0,0027 & 0,002 \\
LNAVM ${ }^{2}$-RIESGO & $-0,1962$ & 0,0027 & 0,002 \\
LNAVM 2 -LADERA & $-0,2781$ & 0,0026 & 0,002 \\
LNAVM $^{2}$-ATG & $-0,1534$ & 0,0025 & 0,002 \\
LNAVM 2 -LNPUNTAJE1 & 0,3653 & 0,0026 & 0,002 \\
\hline
\end{tabular}

Fuente: construcción propia

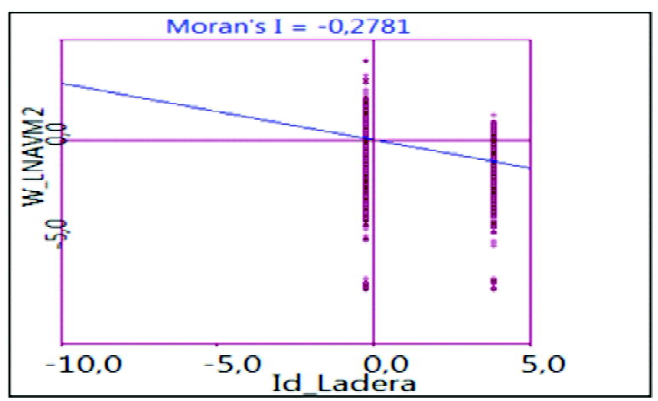

I: -0,2781 P-Value: 0,002 Sd: 0,0026 Permut: 499

\section{Gráfica 4.}

Fuente: elaboración de los autores con ayuda de sotware GEODA. 
El índice de Moran = -0,2781 con un grado de significancia de $\mathrm{P}=0,002$, que nos calculó el programa muestra una relación negativa y débil entre la variable ambiental LADERA que se observa en el eje $X$ y el log. del avalúo por metro cuadrado de los predios vecinos (W-LNAVM ${ }^{2}$ ) que se registra en el eje vertical.

Esta relación indica que a medida que aumenta la proximidad a una ladera disminuye el log. del avalúo por metro cuadrado de las viviendas de los vecinos en la ciudad de Manizales.

La debilidad de esta relación negativa, puede estar ocasionada porque existen datos que se alejan de la tendencia, especialmente, en el III cuadrante, sin embargo, el grado de significancia de 0,002 puede avalar estos resultados, aunque se puede pensar que el modelo que mejor recoge los efectos marginales y espaciales es el Spacial-lag por cuanto el mejor impacto sobre el avalúo de los predios fue la variable ladera que con un coeficiente de 0,374 fue menor en la confirmación al considerar los rezagos espaciales.

El mapa 9 muestra un análisis multivariante Lisa de ladera para indicar los clústers que se forman en la ciudad con esta relación: se observa cómo este tipo de peligro afecta el avalúo de los predios vecinos, por ejemplo, los escasos puntos rojos se ubican donde hay un alto riesgo de ladera y, sin embargo, los avalúos de estos predios vecinos a la ladera son costosos (caso tejares). Las zonas azules dejan ver, cómo el bajo riesgo de ladera no eleva el avalúo de los predios en muchas partes de la ciudad, sin embargo, el color rosado deja mirar el efecto que tiene el peligro de ladera en el bajo avalúo de los predios vecinos (caso perímetro urbano). El bajo efecto de las laderas sobre los altos avalúos de los predios vecinos se muestran en las partes menos peligrosas de la ciudad como el centro y otros sitios ubicados a los lados de las avenidas Santander y Paralela que se ven en el mapa pintados de color lila.

A continuación se hace un análisis Bilisa cluster map entre ladera y w-lnavm².

El color rojo (High-High) indica alto peligro de ladera rodeada de altos avalúos catastrales, el color azul (Low-Low) muestra bajo peligro de ladera con casas de bajo costo alrededor. El color lila (LowHigh) deja ver las zonas sin laderas con altos avalúos y el último color rosado (HighLow) muestra el bajo valor de las viviendas que están ubicadas cerca a las laderas.

El grado de significancia de esta relación también se mapea con los mismos colores verdes que se presentan a continuación.

El programa fija el nombre de Bilisa significante mapa ladera-wlnavm ${ }^{2}$ a los grados de significancia de la relación Ladera y avalúo de las casas vecinas que va desde el menos significante (color verde claro $\mathrm{P}=0,05)$ hasta el más significante (color verde obscuro $\mathrm{P}=0,0001)$. 


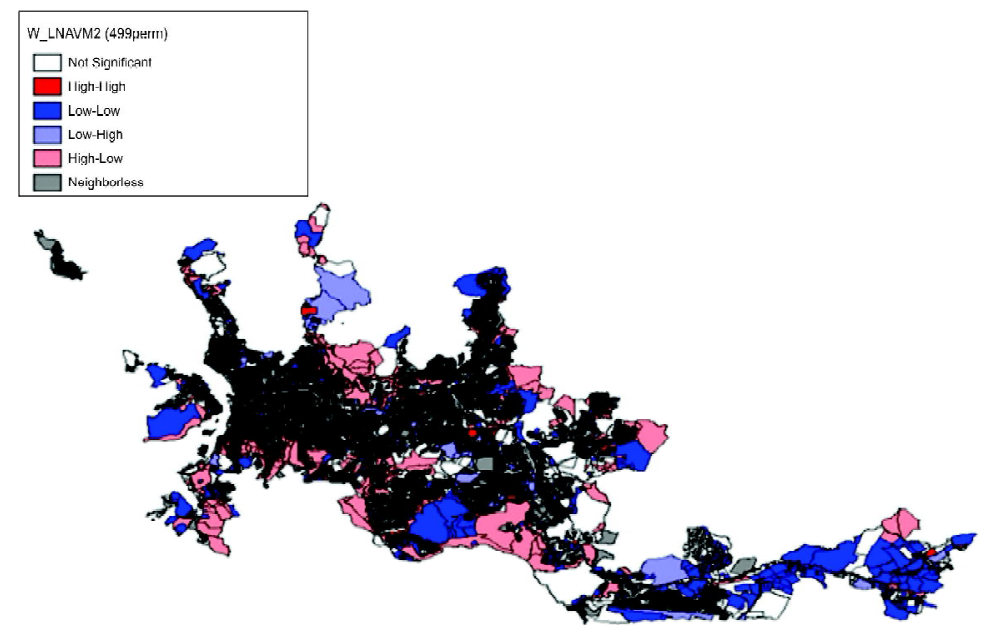

Mapa 9. Análisismultivariante lisa de ladera $-\mathrm{w}$-.inavm ${ }^{2}$

Fuente: elaboración de los autores con ayuda de sotware GEODA y con base en datos del IGAC.

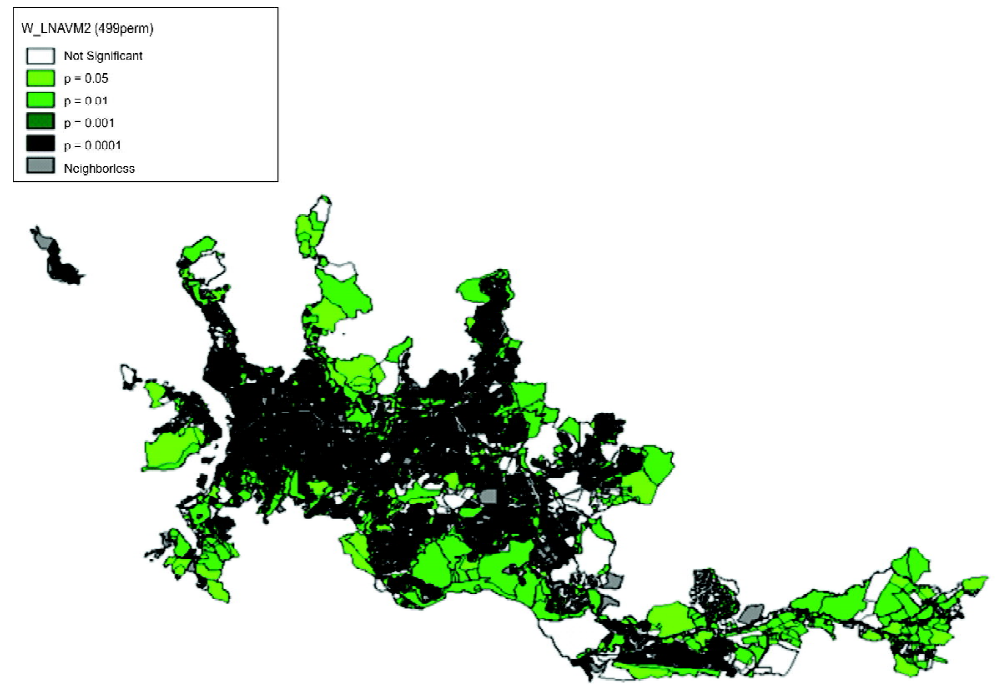

Mapa 10. Grado de significancia del Lisa Ladera-W-LNAVM ${ }^{2}$

Fuente: elaboración de los autores con ayuda de sotware GEODA y con base en datos del IGAC. 


\section{Análisis confirmatorio}

En esta sección se analiza la relación entre el avalúo de la vivienda y las variables que componen el "paquete de características", a través de la estimación del modelo de precios hedónicos con efectos espaciales que es el objetivo de este trabajo y la respuesta a la pregunta planteada inicialmente. En la Tabla 4 se presenta un resumen comparativo de los resultados obtenidos en las regresiones que el programa Geoda corrió utilizando los tres modelos (OLS, Spacial-Lag y Spacial.error).

Tabla 4. Resumen de los efectos marginales y espaciales

\begin{tabular}{|l|c|c|c|}
\hline Variables & OLS & Spacial-lag & Spacial-error \\
\hline W-LNAVM2 & & 0,2087 & \\
LNIC & 0,659 & 0,58 & 0,583 \\
RIESGO & $-0,2174$ & $-0,1196$ & $-0,10$ \\
LADERA & $-0,4786$ & $-0,3741$ & $-0,5386$ \\
ATG & $-0,3848$ & $-0,2195$ & $-0,3455$ \\
LNPUNTAJE1 & 0,90639 & 0,7514 & 0,74 \\
LAMBDA & & & 0,6669 \\
\hline
\end{tabular}

Fuente: elaboración de los autores.

Antes de analizar los coeficientes obtenidos es necesario examinar la consistencia de los resultados. En los anexos 1,2 y 3 se observa que la mayoría de los coeficientes son significativos, los test de significatividad global permiten afirmar que todas las variables explicativas son simultáneamente relevantes para la determinación del logaritmo del avalúo de los predios por metro cuadrado en la ciudad de Manizales.

$\mathrm{Al}$ analizar los resultados de la regresión indicados en la Tabla 4, se desprende que existe una relación negativa, significativa entre las variables ambientales Riesgo, Ladera y ATG y el logaritmo del avalúo por metro cuadrado del predio. Las únicas variables que muestran una relación directa con el log. del avalúo por metro cuadrado de los predios son: el logaritmo del índice de construcción LNIC y el log. del índice de la calidad de la vivienda LNPUNTAJE1. Estos resultados muestran alto grado de significancia en la determinación del log del avalúo de los predios por metro cuadrado de las construcciones.

Se observa que los coeficientes que más influyen en el avalúo por metro cuadrado de los predios son el log. Del índice de calidad de la vivienda que por el modelo OLS influye en un $0,9063 \%$, por el modelo spacial-lag (que recoge rezagos espaciales) da $0,7514 \%$ y por el spacialerror (con errores espaciales) da $0,7407 \%$, no obstante los tres modelos 
tienen un buen grado de significancia. El efecto espacial en el caso de la variable dependiente se puede interpretar, así: por un aumento del $1 \%$ en el avalúo del predio por metro cuadrado del vecino, el avalúo del predio analizado se incrementa en $0,21 \%$

La otra variable altamente significativa que influye en el avalúo de la vivienda es el log. Del índice de construcción, donde el coeficiente tiene un valor de 0.58 , indicando que un aumento del $1 \%$ en los avalúos vecinos incide en un $0,58 \%$ en el avalúo del predio por metro cuadrado. Las variables que marcan una relación positiva, incrementan el avalúo de la vivienda, cuando aumentan y las que tienen una relación inversa, disminuyen el avalúo de la vivienda.

Tabla5. Resultados del modelo OLS

\begin{tabular}{|c|c|c|c|c|c|c|c|c|c|}
\hline Variable & \multicolumn{3}{|c|}{ OLS } & & SPACIAL & & & SPACIAL & \\
\hline & Coeffici & Std.Erro & t-Statisti & Coeffici & Std.Erro & t-Statisti & Coeffici & Std.Erro & t-Statisti \\
\hline R-squar & 0,54947 & & & 0,61127 & & & 0,74347 & & \\
\hline F-statisti & 16537 & & & & & & & & \\
\hline $\begin{array}{l}\text { Log } \\
\text { likelihoo }\end{array}$ & -105756 & & & -101083 & & & -907461 & & \\
\hline Akaike i & 211524 & & & 202180 & & & 181504 & & \\
\hline $\begin{array}{l}\text { W_LNAV } \\
M 2\end{array}$ & & & & $\begin{array}{l}0,20872 \\
7\end{array}$ & $\begin{array}{l}0,00221 \\
9023\end{array}$ & $\begin{array}{l}94,0625 \\
4\end{array}$ & & & \\
\hline CONSTA & 9,60712 & 0,01403 & 684,685 & 7,51923 & 0,02646 & 284,122 & 10,1352 & 0,014081 & 719,7518 \\
\hline LNIC & 0,65916 & 0,00776 & 84,8433 & 0,58073 & 0,00726 & 79,9661 & 0,58326 & 0,006543 & 89,13158 \\
\hline Id_Riesg & 0,2174 & 0,03084 & $-7,0491$ & $-0,1146$ & 0,02866 & $-3,9987$ & $-0,1008$ & 0,036282 & $-2,77937$ \\
\hline IdLadera & $-0,4786$ & 0,02368 & $-20,212$ & $-0,3741$ & 0,02204 & $-16,972$ & $-0,5386$ & 0,023675 & $-22,7495$ \\
\hline Id_ATG & $-0,3848$ & 0,02396 & $-16,055$ & $-0,2195$ & 0,02232 & $-9,8330$ & $-0,3455$ & 0,021531 & $-16,0472$ \\
\hline LNPUNT & 0,90639 & 0,00401 & 225,737 & 0,75138 & 0,00399 & 187,994 & 0,74070 & 0,003389 & 218,5501 \\
\hline AJE1 & 14 & 5237 & 9 & 58 & 6852 & 4 & 6 & 182 & \\
\hline LAMBD & & & & & & & 0,66690 & 0,003206 & 208,0148 \\
\hline MULTICI & 6,73400 & & & & & & & & \\
\hline JarqBera & 5298114 & & & & & & & & \\
\hline $\begin{array}{l}\text { Breusch- } \\
\text { Pagan }\end{array}$ & $\begin{array}{l}153603, \\
7\end{array}$ & & & $\begin{array}{l}135117, \\
5\end{array}$ & & & $\begin{array}{l}131667, \\
4\end{array}$ & & \\
\hline Koenker & 6930,66 & & & & & & & & \\
\hline $\begin{array}{l}\text { Likelihoo } \\
\text { d Ratio } \\
\text { Test }\end{array}$ & & & & $\begin{array}{l}9345,70 \\
7\end{array}$ & & & $\begin{array}{l}30019,8 \\
8\end{array}$ & & \\
\hline
\end{tabular}

Fuente: elaboración de los autores.

En la Tabla 5 se observan los resultados del modelo OLS sin modificar las variables, encontrando las mismas relaciones positivas y negativas del modelo Espacial lag y Espacial-error. La gran diferencia entre los tres modelos está marcada en los valores de los coeficientes y los errores estándar que 
disminuyeron al pasar del modelo OLS al modelo spaciallag y spacial-error, También se observan mejoras en el $\mathrm{R}^{2} \mathrm{y}$ en la prueba de heterocedasticidad.

Las variables ambientales disminuyen en un alto porcentaje el avalúo y precio de la vivienda por los peligros que representan para la integridad de las personas, como se va a registrar en el próximo capítulo de conclusiones.

\section{CONCLUSIONES}

1- Mediante la valoración hedónica y a través de técnicas de econometría espacial se determinó el efecto marginal de las variables estructurales, de calidad y ambientales en el avalúo de la vivienda en Manizales. En promedio,las viviendas cercanas a las áreas de riesgo reducen el precio hasta un $11,46 \%$, el vivir cerca de una ladera lo afecta en un $37,41 \%$ y el encontrarse en zona de tratamiento geotécnico hasta un 21,95\%. El índice de construcción afecta el avalúo de la vivienda en $58 \%$ y la calidad de la vivienda incide en $75 \%$, cuando utilizamos el modelo spacial-lag. Estos coeficientes fueron mejores que los obtenidos en los modelos spacial-error y mínimos cuadrados ordinarios ${ }^{2}$.

2- Las técnicas de econometría espacial mostradas por el programa GEODA suministrado por Luc Anselin, lograron mostrar y cuantificar las interrelaciones que tienen los datos en el espacio geográfico, encontrándose que la autocorrelación espacial es el patrón que mejor describe los datos en la ciudad de Manizales.

3- El resultado del análisis confirmatorio, resumido en las tablas 9 y 10 , mostró que el modelo que más se acomoda en el caso de la variable riesgo es el spacial-error con menores $\mathrm{R}^{2}$, criterio de Akaike y una reducción de los errores con relación a los otros modelos OLS y Spacial-lag.

4- La estimación de modelos de precios hedónicos permitió conocer cuáles son los determinantes más importantes en el avalúo de unavivienda y la influencia de cada uno de ellos, de acuerdo con los objetivos planteados.

5- Una de las bondades de la metodología de regresiones geográficamente ponderadas (GWR) es que permite ver la distribución espacial de los coeficientes locales. En los mapas realizados se encontró que el efecto de las variables índice de construcción de la vivienda IC, el índice de calidad de la vivienda PUNTAJE1 y las variables ambientales LADERA y ATG con una perfecta significancia son mostrados los clústers donde los predios se relacionan con los predios vecinos, teniendo en cuenta cada una de estas variables.

El coeficiente de riesgo, pasó de tener un valor de - 0.2174 en la regresión con los OLS a un valor inferior de 0.1146 en la regresión spaciallag, reflejando con esto que haciendo un análisis espacial, la incidencia de la variable riesgo en el precio de la vivienda en Manizales es 10 veces menor que si utilizamos el simple modelo de mínimos cuadrados ordinarios OLS. 
6- Los test de significatividad global permiten afirmar que todas las variables explicativas son simultáneamente relevantes para la determinación del logaritmo del avalúo de los predios en todos los modelos estimados.

7- La base de datos construida con información georreferenciada, sirvió para conocer los determinantes de los avalúos de las viviendas y estar más cerca del precio de mercado.

8- La ecuación de precios hedónicos hallada permite observar la importancia cuantitativa que tiene cada una de las variables utilizadas en la fijación del avalúo de la vivienda para la ciudad de Manizales, como se evidencia a continuación:

$$
\begin{gathered}
\text { LNAVM }^{2}=7,52+0,58 \text { LNIC } \\
-0,1146 \text { RIESGO-0,3741LADERA } \\
-0,2195 \text { ATG + 0,75LNPUNTAJE1 } \\
+0,20872 \mathrm{~W}+\mathrm{U}
\end{gathered}
$$

Donde 0,20872W es el efecto espacial, las otras son las variables explicativas con su correspondiente efecto marginal o coeficiente y U son los posibles errores que todavía quedan en el modelo Spaciallag. En esta función se observan los atributos de la vivienda como regresores de la función hedónica, cuantificando los efectos propuestos en este trabajo.

\section{Aplicaciones}

A partir de esta ecuación hedónica es posible elaborar un modelo de determinación y simulación de precios que permita, entre otras cosas, las siguientes aplicaciones:

Si las características del proyecto (o bien raíz) están dadas, es posible determinar el valor de mercado de éste.

Si se desea alterar una de las características (por ejemplo, índice de construcción, calidad de la vivienda y variable ambiental), es posible determinar cuánto valora el mercado el cambio. Para ello, se estima el precio en ausencia de la característica y luego se la compara con aquél que la incorpora. El diferencial entre ambas predicciones representa la valorización que según el modelo debiera experimentar el bien raíz producto de la ejecución del proyecto.

Si se desea diseñar un proyecto, es posible determinar la combinación óptima de atributos que éste debe contener, de manera de maximizar el valor del proyecto frente a su costo (es decir, cuál es la combinación más rentable entre superficie, área construida, calidad y externalidades).

La metodología permite identificar zonas de potencial desarrollo urbano, anticipando sus valorizaciones futuras. Para ello, se estudia las áreas de tratamiento geotécnico ATG, las laderas y los riesgos, de manera de proyectar y predecir su proceso de crecimiento.

Por último se recomienda a las oficinas de planeación georreferenciar otros 
atributos y características que no se encontraron en la base datos para perfeccionar el modelo, especialmente falta involucrar más variables ambientales como los niveles de ruido, las partes suspendidas de gases contaminantes, las basuras, etc. También faltan los niveles de criminalidad y otras externalidades que pueden servir para realizar futuras investigaciones.

\section{R eferencias}

Anónimo. (s.f.). www.uv.es/ ssaz/ hedónicos.pdf. Recuperado de www.uv.es/ ssaz/hedónicos.pdf.

Anselin, L. (1988a). Spacial Econometrics: Methods and models. The netherlands: Kluwer Academic publishers.

Anselin, L., \& Getis, A. (1992). Spatial Statistical Analysis and Geographic Information Systems. Ciudad: Editorial.

Arias, H. (2012). Aglomeración industrial en el centro oriente colombiano. Apuntes CENES, 31 (53), 81-109.

Asqueta, D. (1994). Valoración económica de la calidad ambiental. Madrid: Mc Graw Hill.

Caridad, J. M. (2008). Metodología de precios hedónicos vs. redes neuronales. Córdoba: Universidad de Córdoba.

Court, A. (1939). Hedonic price indexes with automotive examples, dinamics of automovile. Ciudad: Editorial.

Cropper, M. (1981). The value of urban amenities. Journal of regional science, 21, 359-374.
Diamond, D. (1980). The relationship between amenities and urban land prices. Land Economics 57, 21-32.

Díaz, M. E., Vanegas, E. A. \& Camacho, J. (2014). Determinación de modelos econométricos para la valoración de tierras rurales en Guatemala. Revista Ciencias Técnicas Agropecuarias, 23 (1), $47-52$.

Duque, J. C. (2011). Infraestructura pública y precios de vivienda: una aplicación de regresión geográficamente ponderada en el contexto de precios hedónicos. Ecos de Economía 15 (33).

Freeman III, M. A. (1979). The Benefits of Environmental Improvements. Washington D.C.: The Johns Hopkins University Press.

Galvis, L. \& Carrillo, B. (2013). Índice de precios espacial para la vivienda urbana en Colombia: una aplicación con métodos de emparejamiento. Economía del Rosario 16 (1), 25-59.

Harris, A. (1981). The Hedonic Technique and the valuation of Environmental quality, in advances in applied microeconomics. Connecticut: Kerry V. Smith. 
Hass, G. (1922). Sales prices as a basis for farm land appraisal. Technical Bulletin of the University of Minnesota. Revista de estudios regionales, 135, 158.

Johnson, M. (1987). CBD Land values and múltiple externalities. Land Economics.

Kolstad, C. (2000). Economia Ambiental. Oxford: Oxford University press.

Krugman, P. (1997). Desarrollo, geografía y teoría económica. Barcelona: Antoni Bosch.

Lancaster, K. J. (1966). A New Approach to Consumer Theory. Journal of Political Economy. 74 (2), pp. 132-157.

Lever, G. (2000). Determinantes del precio de la vivienda en Santiago: Una estimación Hedónica. Paper. Santiago, Chile: Editorial.

Li, M. (1980). Micro-Neighborhood externalities and hedonic prices. Land economics, 125-141.

Lozano, N. (2011). Is the Price Right? Assessing Estimates of cadastral values for Bogotá, Colombia. California, USA: Geoda Center Arizona State University.

Maller, G. K. (1977). A note on the use of property values in estimating marginal willingness to pay for environmental quality. Journal of Environmental Economics and Management, 4, 355369.

Manning, C.A. (1988). The determinants of intercity home building site price differences. Land Economics. 64 (1), 114.
Mendieta, J. C. (2001). Manual de valoración económica de bienes no mercadeables. Bogotá: Universidad de los Andes, Facultad de Economía.

Moran, P. (1948). The Interpretation of Statistical Maps. Journal of the Royal Statistical Society B. (10), 243-251.

Moreno, R. (2000). Técnicas económetricas para el tratamiento de datos espaciales: la econometría espacial.Barcelona: Edicions Universitat de Barcelona.

Paelinck, J. H. (1979). Spacial Econometrics. Famborough: Saxon House.

Palmquist, R. (1984). Estimating hte demand for the characteristics of housing. Review economics and statistics, 394-404.

Peiser, R. (1987). The determinants of non residential urban land values. J. Urban Economics. 22 (3), 340-360.

POT. (2007). Plan de ordenamiento territorialAcuerdo $N^{\circ} 663$ de 13 sep. Manizales.

Ramírez, D. E. (2006). Acumulación de capital y competitividad del territorio. En D. Ramírez, Territorio y competitividad (págs. 32 - 74). Manizales: Blanecolor.

Revollo, D. A. (2009). Calidad de la vivienda a partir de la metodología de precios hedónicos para la Ciudad de Bogotá Colombia. Revista digital universitaria de la Unam 10 (7).

Ridker, R.G. (1967). The determinants housing prices and the demand for clean air. Journal Environmental Economy. 5 (1), 81-102. 
Roback, J. (1982). Wages rents and the quality of life. Journal Political Economy, 12571258.

Rosen, S. (1974). Hedonic prices and Implicit Markets. Ciudad: Editorial.

Rubinfeld, D. J. \& Harrison, D. J. (1978). Hedonic Housing Prices and the Demand for Clean Air. Journal of Enviromental Economics and Management 5, 81-102.

Sánchez, R. (2008). Econometría espacial en los modelos de precios hedónicos. Texas: Cedlas-Unlp-University of Texas at Austin.

Student. (1914). The elimination of spurios correlation due to position in time or space. Biometrika, 10, 179-180.
Valencia, G. L. (2012). Valoración hedónica de la vivienda, Una aplicación con variables ambientales. Manizales: Repositorio Institucional Universidad de Manizales.

Velásquez, L. (2011). La importancia de los bienes públicos en la calidad de vida local. El casode Manizales, Colombia. Manizales: Centro de Estudios Regionales Cafeteros yEmpresariales (CRECE).

Wallace, H. (1926). Comparative farmland values in Iowa", Journal of Land and Public Utility Economics. Revista de estudios regionales, $385,392$.

Waught, F. V. (1929). Quality as a Determinant of Vegetable Prices. New York: Columbia University Press.

Witte, A. H. (1974). An Estimate of a Structural Hedonic Price. Cuadernos de Economía, 1151-1174. 